\title{
Sujeitos e(m) experiências: estratégias micropolíticas no contexto da reforma psiquiátrica no Brasil
}

| ${ }^{1}$ Ana Paula Müller de Andrade, ${ }^{2}$ Sônia Weidner Maluf |

Resumo: Este artigo discute os processos de desinstitucionalização desencadeados pela reforma psiquiátrica brasileira e as estratégias micropolíticas relacionadas a esses processos. Os dados que subsidiam nossas discussões advêm de uma pesquisa etnográfica realizada nos anos de 2010 e 2011, nas cidades brasileiras de Joinville, Santa Catarina, e Barbacena, Minas Gerais, assim como em Torino, Trieste e Gorizia, na Itália, com o objetivo de realizar uma análise crítica da reforma psiquiátrica brasileira do ponto de vista dos chamados usuários e usuárias dos serviços de saúde mental. Os aspectos aqui discutidos mostram como as experiências dos sujeitos nesses serviços estão marcadas pela definição de lugares relacionais e hierárquicos, bem como por processos complexos de (des)subjetivação, onde se engendram estratégias micropolíticas de sujeição e resistências. Apontam para a necessidade de construir diferentes maneiras de operar com as concepçôes relacionadas aos sujeitos, suas experiências e modos de agir nos processos de desinstitucionalização.

Palavras-chave: reforma psiquiátrica; desinstitucionalização; modos de subjetivação; experiência; micropolítica.

\author{
1 Universidade Federal de \\ Pelotas, Enfermagem. Pelotas- \\ RS, Brasil (psicopaulla@yahoo. \\ com.br). \\ ${ }^{2}$ Universidade Federal de Santa \\ Catarina, Departamento de \\ Antropologia. Florianópolis-SC \\ (soniawmaluf@gmail.com).
}

Recebido em: 13/03/2015 Aprovado em: 11/08/2015 
As transformaçōes decorrentes da reforma psiquiátrica foram e são responsáveis por experiências distintas, vividas pelos sujeitos que direta ou indiretamente se relacionam com o campo da saúde mental. Tendo como uma de suas propostas uma mudança cultural no que diz respeito à relação da sociedade com a loucura, a reforma psiquiátrica motivou processos de desinstitucionalização, bem como desencadeou reflexões, contrárias ou favoráveis aos mesmos.

Tais processos, legitimados pela Política Nacional de Saúde Mental (BRASIL, 2001), representaram mudanças objetivas e subjetivas na vida dos sujeitos, uma vez que possibilitaram a desospitalização daqueles com história de longas internações em hospitais psiquiátricos, assim como representaram a reorientação do modelo de assistência psiquiátrica, através da constituição de uma rede de serviços abertos que permitiram que "usuários/as" pudessem ir e vir de suas casas, retomar laços sociais e transitar pelas cidades.

O processo da reforma psiquiátrica brasileira se desenvolveu num contexto mais amplo de reformas psiquiátricas desencadeadas em outros países e foi amparado em uma concepção contra-hegemônica ao modelo vigente até esse momento, baseado nos princípios da psiquiatria clássica como a custódia e o isolamento dos loucos. Tal modelo, à época, foi reconhecido como ineficiente nas suas vertentes práticas e teóricas, como mostram os trabalhos de Foucault (1997), Goffman (2001) e Cooper (1989). Para Amarante (1996, p. 14), a reforma psiquiátrica é "um processo bastante inovador, original e prolífero, permeado por inúmeras iniciativas de transformação, com o surgimento de novos atores e protagonistas e uma emergente produção teórica [...]".

O projeto político mais amplo desses processos é a desinstitucionalização, entendida aqui como um "trabalho prático de transformação que, a começar pelo manicômio, desmonta a solução institucional existente para desmontar (e remontar) o problema" (ROTELLI; LEONARDIS; MAURI, 2001, p.n29). Nesse sentido, a desinstitucionalização se amplia para os diferentes âmbitos da reforma psiquiátrica que, ao avançar em seus processos, institui novos modos de subjetivar a experiência do e com o sofrimento mental.

No intuito de discutir alguns aspectos relevantes desses processos, tomamos como referência os dados de uma pesquisa etnográfica ${ }^{1}$ que teve como objetivo realizar uma análise crítica da reforma psiquiátrica brasileira do ponto de vista dos usuários e das usuárias dos serviços de saúde mental. 
Durante a pesquisa de campo, pudemos compartilhar experiências importantes, tanto através de narrativas quanto nas observações feitas durante as atividades acompanhadas na micropolítica da vida cotidiana dos sujeitos. Para Guattari e Rolnik (2008, p. 158), a micropolítica se institui a partir de agenciamentos, desencadeados no nível das subjetividades individuais e coletivas. Para os autores, os "processos de transformação que se dão em diferentes níveis de experimentação social às vezes podem ser mínimos e, no entanto, constituir o início de uma mutação muito maior. Ou não". As experiências e trajetórias dos sujeitos em geral eram narradas tendo como foco algum tipo de "crise", que variavam em seus contextos, mas que se aproximavam nas suas resoluções. O que as aproximava era o fato de terem como "resolução" a procura ou encaminhamento para algum tipo de serviço de saúde, especialmente de saúde mental.

Tais experiências poderiam ser analisadas a partir de várias perspectivas. Contudo, nossa proposta foi compreendê-las de um ângulo que privilegiasse o ponto de vista dos sujeitos que por algum motivo utilizaram os serviços de saúde mental, por entendermos que o ponto de vista deles favoreceria uma análise crítica do que temos chamado e reconhecido como o processo da reforma psiquiátrica.

Referimo-nos à reforma psiquiátrica como processo, fundamentalmente porque, ao considerar o ponto de vista de "usuários" e "usuárias" sobre suas experiências de modo simétrico ao nosso, tivemos a possibilidade de vislumbrar não apenas outra perspectiva sobre um mesmo processo mas, sobretudo, outros processos. Não se trata, no entanto, de reificarmos a alteridade, nem de outorgarmos um lugar comum e estático a estas pessoas, pois, como percebemos no desenvolvimento da pesquisa, os lugares são relacionais, contingenciais e se constroem e se ocupam de diferentes maneiras.

\section{O caminho metodológico da pesquisa}

O trabalho de campo da pesquisa foi desenvolvido durante nove meses do ano de 2010, na cidade de Joinville, Santa Catarina, escolhida como sendo o "local" de onde seria possível analisar o processo "nacional” de reforma psiquiátrica. Além disso, também foi realizada uma pequena incursão etnográfica na cidade de Barbacena, Minas Gerais, e visitas aos serviços de saúde mental das cidades de Torino, Trieste e Gorizia, na Itália. Não realizamos um estudo comparativo, apenas buscamos nestas realidades elementos que ampliassem nossa capacidade de análise. 
A escolha de um trabalho de campo mais denso na cidade de Joinville se deu pelo fato de a mesma apresentar uma experiência significativa no que se referia às transformações na assistência psiquiátrica e à construção de uma política municipal de saúde mental guiada pela Política Nacional de Saúde Mental. A realidade local permitia reconhecer dialeticamente as possíveis inter-relaçôes do nível micro com o nível macro bem como as conexões entre os diferentes planos do processo da reforma psiquiátrica.

Os sujeitos da pesquisa eram homens e mulheres adultos, em sua maioria pertencentes às classes populares urbanas, que tinham em comum o fato de frequentarem ou já terem frequentado serviços de saúde mental. Ressaltamos que, se não fossem os serviços de saúde mental criados a partir do processo da reforma psiquiátrica brasileira, tais pessoas estariam internadas em hospitais psiquiátricos. Muitas delas eram egressas dos mesmos; outras, por motivos diversos, eram internadas nos hospitais psiquiátricos ainda existentes. Outro aspecto importante entre tais sujeitos era o fato de todos usarem ou já terem usado algum tipo de psicofármaco.

O foco do trabalho de campo não foi um grupo ou local específico, mas pessoas que moravam e se deslocavam nas cidades e participavam de atividades ligadas ao "campo da saúde mental". Ao conversar com os primeiros interlocutores e também outras pessoas da cidade sobre a pesquisa, estas indicavam pessoas que julgavam que poderiam participar, por sua vez, sabendo da pesquisa, convidavam para participar de outras atividades e assim o trabalho foi sendo desenvolvido, aos moldes das redes sociais, como sugerido por Bott (1976).

A opção pela abordagem etnográfica - entendida não apenas como um conjunto de procedimentos e técnicas, mas também como uma perspectiva que permite articular os dados empíricos com a teoria - se deu pela possibilidade de enfatizar os diferentes discursos e práticas sociais no contexto da reforma psiquiátrica.

\section{Sujeitos, experiências e relações}

Ao iniciarmos a pesquisa, tínhamos a ideia de trabalhar com as categorias de usuárias e usuários, familiares e trabalhadores do campo da saúde mental para situar os sujeitos, em que ser ou não paciente diagnosticado aparecia como uma linha de diferença entre eles. Entretanto, tais definições foram desde cedo borradas pelos dados que emergiram da pesquisa de campo. Em diversos 
momentos, nas conversas com os/as interlocutores/as, era necessário um esforço

para situá-los/as, seja porque um usuário era também um familiar, seja porque uma trabalhadora era também uma usuária, dentre outras situaçôes.

Numa das conversas com Mateus, ${ }^{2}$ um interlocutor, evidenciamos tal dificuldade quando ele disse: "tu pode perguntar isso para a minha mãe, eu não lembro direito o que eles tinham dito... ah tu também pode conversar com ela pro teu trabalho, ela tem depressão, toma remédio...”. Em sua fala, Mateus situava sua mãe como familiar e também como uma pessoa diagnosticada e demonstrava a precariedade destas categorias.

Tal precariedade apareceu com vigor nos dados de campo, o que nos fez pensar tais categorias como variáveis, uma vez que reconhecemos uma circularidade de posições ocupadas pelo mesmo sujeito. Aquele/a que era familiar também poderia ser alguém com diagnóstico, usuário/a do sistema de atenção à saúde; aquele/a que era diagnosticado e usuário poderia ser também familiar e, algumas vezes, aquele/a que era trabalhador/a poderia ter recebido um diagnóstico como ser também familiar. Várias combinações acabaram aparecendo, o que nos alertava para a intercambialidade de posições.

Entendemos que tais posições, mesmo que precárias, se constituem nas relações de poder presentes no contexto da reforma psiquiátrica e tal como sugeriu Scott (1999) é necessário

[...] "tornar visível a atribuição de posições de sujeito" (Spivak), não no sentido de capturar a realidade dos objetos vistos, mas de tentar compreender as operaçôes dos complexos e mutáveis processos discursivos pelos quais identidades são atribuídas, resistidas ou abraçadas, e quais processos são ignorados e, de fato, conseguem seu efeito precisamente porque não são percebidos (SCOTT, 1999, p. 40).

Nesse sentido, é preciso salientar o caráter relacional, contingencial e hierárquico das posiçôes que tais sujeitos ocupam, especialmente os situados na posição de "usuários/as", ${ }^{3}$ pois esta extrapola a condição social dos mesmos, já que sobre eles se inscrevem, para além dos determinantes socioculturais, a normativa biomédica e o peso, senão de uma internação em hospital psiquiátrico, o de um diagnóstico psiquiátrico levado a suas últimas consequências.

Ao conversar com Eva, uma interlocutora que teve seus filhos dados em adoção em função de suas internações psiquiátricas e posterior interdição judicial, reconhecemos tanto o caráter relacional quanto hierárquico de sua condição de diagnosticada e de paciente. Eva, apesar de ser considerada inapta pelo Estado 
para as atividades da vida civil e curatelada pela mãe, acompanhava seus familiares e alguns amigos para diferentes atividades, como ir ao banco, lotéricas e/ou ao supermercado. Suas experiências nos faziam perceber que ainda que fosse destituída de sua condição de cidadã na sua relação com o Estado, no contexto de suas relaçôes sociais se constituía de outra forma, pois era encarregada de atividades que exigiam aptidão e responsabilidades.

A atribuição da posição de "usuários" e "usuárias" é dada, neste contexto, prioritariamente pelo discurso biomédico e também por outros fatores que gravitam em torno de saber falar em público, pertencer a uma classe social mais favorecida economicamente e compartilhar de um conjunto de expressóes/ palavras tidas como "científicas", como a nomenclatura médica por exemplo. Quanto a este último aspecto, uma situação vivida em campo é ilustrativa deste argumento e por isso será descrita a seguir.

Durante a reunião do núcleo da luta antimanicomial, Daniel (interlocutor) pede a palavra e começa uma explicação sobre os benefícios da medicação solicitada via Ministério Público por uma outra participante (também "usuária") e diz: "eu vou te explicar (se dirigindo a outra "usuária") porque tu não sabe, o Zyprexa é uma medicação de ponta, de última geração, ela não tem muitos efeitos colaterais porque atua diretamente nos neurotransmissores." Explica detalhadamente o que entende como sendo os benefícios de tal medicamento, como se estivesse lendo a bula do mesmo. Ao final (se dirigindo a mim) diz: "a gente tem que explicar isso pra eles [os "usuários/ as"]” (fragmento do diário de campo)

Esta última frase, aliada a seus extensos conhecimentos sobre a medicação, parecia colocá-lo no exterior da posição de "paciente", a partir de seu ponto de vista, tendo "ele" que explicar para "eles" tais benefícios. Tal situação mostra o caráter relacional e na maior parte das vezes hierárquico dessas diferentes posições.

Outro aspecto importante do contexto pesquisado foi a apropriação do discurso biomédico por parte dos "usuários" e "usuárias". "Tal apropriação pode ser pensada não apenas como recurso para a negociação com o mundo, mas também como uma forma de ordenação das experiências e uma possibilidade de emergência enquanto sujeito no contexto dos serviços de saúde.

Não foi apenas na situação descrita que pudemos perceber isso, mas em outras em que os sujeitos falavam de suas experiências a partir da lógica e da linguagem biomédica, ainda que articulada com outras lógicas que em geral diziam respeito a seus contextos culturais. A linguagem é transformada e mesmo ressignificada pelos sujeitos. Ela ganha novos significados através dos quais se aproxima do 
contexto cultural do qual passa a fazer parte e, assim, se articula aos demais modelos interpretativos daqueles que dela fazem uso.

Alves (2010, p. 51), na discussão que fez sobre o uso da linguagem psiquiátrica entre sujeitos leigos no norte de Portugal, diz que ela é utilizada quando os mesmos não encontram palavras para definir comportamentos e atitudes consideradas anormais. Para a autora:

[...] são as pessoas quem têm um historial de contacto com a psiquiatria, ou por vezes, pessoas com maior escolaridade, que tendem a aproximar o seu modo de falar sobre a doença mental à racionalidade biomédica. Isto traduz muitas vezes a incorporação do paradigma moderno da ciência sobre o que é o conhecimento verdadeiro ou socialmente válido.

Nesse sentido, a linguagem parece ser mais um elemento a configurar hierarquias no campo da reforma psiquiátrica, seja pelo uso de uma nomenclatura distante do contexto de significação dos pacientes, como é o caso dos F's - que compõem a classificação dos transtornos mentais do Código Internacional das Doenças (CID) -, seja pela pouca consideração da linguagem cultural por parte dos profissionais da área biomédica.

Em seu trabalho sobre o elevado número de diagnósticos psiquiátricos no Vale do Jequetinhonha, Cardoso (2002) mostrou que este fenômeno resultava de um descompasso entre o modelo clínico adotado pelos profissionais (baseado em categorias nosológicas) e o modelo/ sistema conceitual daquela população, em que os clínicos tomavam o primeiro como aquele com a capacidade de interpretação daquela realidade e os demais como dotados de certa "ignorância" sobre a mesma. Diz a autora: "De acordo com um dos médicos, só pelo "modo de falar", o "jeito com que entra no consultório", ele já sabia qual era a "doença” do paciente" (CARDOSO, 2002, p. 92).

Nilza, uma interlocutora, articulando e se apropriando da linguagem biomédica, ao contar sua experiência de diagnóstico e tratamento, em determinado momento de seu relato explicou quais eram, na sua percepção, os motivos que haviam levado o médico a diagnosticá-la como esquizofrênica. Em seu relato, dentre outras coisas, deixava transparecer que o fato de ser uma mulher, casada e mãe, da qual a sociedade em geral espera um determinado tipo de atitude, fazia com que o estranhamento do médico em relação ao seu comportamento aumentasse. Disse ela: “[...] foi por isso, eu tinha feito tudo aquilo, andava daquele jeito, aí cheguei lá, tinham chamado a ambulância e mais 
a polícia, e ele disse que eu era esquizofrênica. Aí eu era esquizofrênica. Ele viu e disse [...]"(fragmento do diário de campo).

Esse movimento de "pensar a partir do que foi pensado" pelo psiquiatra para lhe conferir tal diagnóstico, demonstra a reflexividade e o trabalho "antropológico" realizado por ela para entender as categorias através das quais o psiquiatra se embasou para lhe conferir tal diagnóstico, bem como do que ela entendia que havia feito para que o mesmo lhe fosse conferido.

O caráter relacional, reflexivo presente nesta e em outras situações, foi bastante significativo no contexto dos sujeitos da pesquisa e demonstram que nas relaçôes estabelecidas no contexto da reforma psiquiátrica vão se constituindo outras possibilidades de experimentar e se relacionar com a loucura.

\section{Processos (des)subjetivantes e estratégias micropolíticas}

"[...] a gente fica com os problemas que o médico põe na cabeça da gente" disse Roger, referindo-se à sua experiência num serviço de saúde mental, quando, em uma consulta psiquiátrica, recebeu o diagnóstico de depressão. Frase precisa e clara para se referir à captura da subjetividade pelo poder biomédico que ocupa um lugar relevante na configuração e constituição dos sujeitos no processo da reforma psiquiátrica. Roger era um homem branco, casado, pertencente às classes populares, que enfrentava problemas conjugais e de relacionamento no trabalho, tão comuns na atualidade. Percebeu-se incomodado e procurou ajuda. Entretanto, sua experiência em tal serviço acabou por gerar outro problema, aquele que o médico colocou na sua cabeça, a depressão.

Tal como percebemos, apesar de tal enunciado ter muita importância na constituição dos sujeitos e na fixação de seus lugares na hierarquia própria do modelo biomédico, há várias maneiras de lidar com ele. Conforme apontaram os dados da pesquisa realizada, os sujeitos sobre os quais se instituem tais enunciados utilizam estratégias diversas. Estas vão desde a utilização do diagnóstico para negociar com o mundo; o uso do mesmo para sobreviver economicamente em um mundo marcado por desigualdades de todo tipo, bem como a sua relativização, como fez Nilza. As pessoas entendem por que foram diagnosticadas desta ou daquela maneira e não acatam passivamente os diagnósticos que lhe são conferidos. 
Além disso, mesmo não usando a expressão "doente mental” para nomear suas experiências, os sujeitos pesquisados assumiam seus diagnósticos específicos, utilizando a linguagem biomédica, ainda que os significados pudessem ser variados. Era através de seu diagnóstico de esquizofrenia que Nilza negociava e buscava direitos, como melhores condições de tratamento, o passe livre que lhe permitia circular pela cidade, enquanto que para o médico, tratava-se de uma doença mental grave e persistente, com sintomas incapacitantes para a vida social.

$\mathrm{O}$ fato de Nilza entender e assumir que era uma esquizofrênica, assim como fazia Eva, que apesar de ser curatelada não deixava de exercer suas atividades sociais quando lhe era solicitado, não significava que ela se sujeitasse totalmente ao mesmo ou a tudo o que esse diagnóstico trazia junto como incapacitante para o sujeito. Aceitar o diagnóstico, nesse contexto, não significava sujeitar-se a ele, mas fazer uso dele para negociar e reivindicar determinada condição no mundo bem como para resistir e subverter o poder prescritivo e normativo do mesmo. Entre os polos opostos da aceitação ou da recusa do diagnóstico feito pelo especialista, existem todas as demais possibilidades de deslocamento e de invenção de novos lugares. Uma situação, vivida durante o trabalho de campo, é bastante ilustrativa nesse sentido:

[...] a reunião já tinha começado quando Daniel chegou. As pessoas se voltam para cumprimentá-lo e seguem na discussão. Ele interrompe e diz: "eu quero falar uma coisa." As pessoas se voltam novamente pra ele, num misto de incômodo e (talvez) curiosidade por ele estar interrompendo a discussão. E então ele, diante dos olhares, diz: "Eu não tô em surto. Eu quero falar uma coisa..." (fragmento do diário de campo).

Esse alerta sobre não estar em surto antecipa o que seria uma reação esperada diante de uma pessoa diagnosticada como esquizofrênica que resolve falar no "momento errado" - está em surto. Se qualquer pessoa pode ser apenas impertinente quando interrompe uma reunião já em curso, no caso de um "paciente mental", ele está sendo mais do que impertinente, está agindo conforme sua doença, está surtado - e por isso, não por sua impertinência, não mereceria ser escutado.

Impertinente ou não, ele precisava posicionar sua fala, esclarecer que não estava em surto. Tal como percebemos, o sujeito capaz de falar e ser escutado é aquele que, não estando em surto, tem o domínio de suas faculdades mentais, sabe quem é e o que faz enfim, é dono de sua razão, sendo assim admitido na comunidade dos que falam e são escutados. 
As ambivalências sobre os sujeitos, com ou sem razão, são condicionadas por alguns fatores que se articulam com um regime psiquiatrizante ainda hegemônico no contexto pesquisado. Entendemos por regime psiquiatrizante, o modo de pensar, perceber e se relacionar com a experiência e a radicalidade da diferença a partir da racionalidade biomédica que, além de classificatória, é também prescritiva.

Não raro, entre os/as interlocutores/as, foi possível ouvir expressões do tipo: "eles [os outros "pacientes"] às vezes ficam assim mesmo, não sabem o que fazem... é porque tão ruim mesmo." Ou então: "Quando a pessoa tá assim, nem sabe o que é, quem é....”. Esses são momentos comumente denominados como de "surto" ou de "crise".

A invisibilidade destes sujeitos, que desaparecem em momentos de surto ou crise e/ou em função do que seria de perda da sua razão, já havia sido descrita por Franca Basaglia no livro intitulado Manicômio, por quê? [Manicomio, perchè??] onde a autora relata uma visita que realizou em um manicômio, mostrando como as práticas ali exercidas desconsideravam os sujeitos. Conta Basaglia (2001, p. 15):

Em um quartinho com uma janelinha via, da grade, uma mulher de meia idade presa à cama. Fizeram-me entrar. Eu, relutante, tinha advertido sobre o sentido de violação, de profanação naquela nossa invasão em seu quarto, em vê-la presa, humilhada, prisioneira, sobre completo domínio de todos. Com os olhos resignados, a mulher nos fixava, enquanto o médico, vestido de branco, falava dela, da sua doença, da sua "maldade", como se ela não estivesse e não pudesse escutá-lo. [tradução livre]

A situação descrita por Basaglia (2001) se assemelha a algumas circunstâncias vividas durante a pesquisa de campo, em que tais sujeitos, esses que são definidos como aqueles que não sabem quem são nem o que são se tornavam invisíveis, ainda que não estivessem em crise. Falava-se sobre eles com eles presentes sem que eles pudessem se manifestar, o que mostrava de forma evidente o sentido dessubjetivador do uso da "terceira pessoa" (DELEUZE; GUATTARI, 2007).

Como argumentou Deleuze (1996), a partir da ideia de Foucault, o sujeito é uma variável, ou melhor, um conjunto de variáveis de enunciado. O sujeito é um dos lugares possíveis no contexto da enunciação. Para Deleuze (1996, p. 63): "Objetar que existem enunciados ocultos é, apenas, constatar que há locutores e destinatários variáveis segundo os regimes ou as condições.”

Voltando às situações em que se falava sobre eles com eles presentes sem que eles pudessem se manifestar, cabe destacar que isso não se deu apenas nas 
relações entre terapeutas e pacientes ou entre os familiares e seus "doentes",

mas também entre os próprios pacientes, estando estes sempre na condição da terceira pessoa, como ficou claro quando Daniel teve que explicar para eles por que eles não sabiam tanto quanto ele sobre a medicação. Naquele momento, Daniel emerge como sujeito que fala sobre eles. Em seu trabalho, Alves (2010, p. 47) argumenta que

Nos discursos na terceira pessoa, ou seja sobre os outros, os nervos [categoria cultural do pensamento leigo utilizada para designar o sofrimento mental] aparecem associados a pessoas consideradas fracas (categoria humana altamente desvalorizada e rejeitada porque interfere com a identidade). Nos discursos na primeira pessoa, quando o próprio se declara nervoso, os nervos referem-se a um fenômeno diferente, quase sempre a situaçôes menos graves e justificadas pelos contextos que despoletam os nervos - aqui a pessoa não é nervosa, mas apenas reagiu com nervos perante determinada situação.

No contexto da nossa pesquisa, os discursos que se referem ao outro na terceira pessoa, não apenas invisibilizaram os sujeitos, mas os retiravam da posição de sujeito, colocando-os fora da possibilidade de uma concepção hegemônica de sujeito presente na nossa sociedade. Ao mesmo tempo evidenciavam o quanto as relações estabelecidas são também relações de poder. Tal como descreveu Foucault (2009, p. 10-11):

Desde a alta Idade Média, o louco é aquele cujo discurso não pode circular como o dos outros: pode ocorrer que sua palavra seja considerada nula e não seja acolhida, não tendo verdade nem importância, não podendo testemunhar na justiça, não podendo autenticar um ato ou um contrato, não podendo nem mesmo, no sacrifício da missa, permitir a transubstanciação e fazer do pão um corpo [...].

Maluf (2011) tem sugerido uma abordagem antropológica do sujeito, não apenas como objeto de análise, mas como categoria central para se compreender o contemporâneo. Para isso, sugere o diálogo com outras teorias que têm pensado prioritariamente o sujeito, como a teoria feminista, a crítica pós-colonial, a psicanálise, e as reflexões Foucault, assim como as de Deleuze e Guattari. Teorias que têm procurado deslocar a ideia de um sujeito unificado, substantivo e autossuficiente, concepção hegemônica na modernidade, para os diferentes processos, regimes e modos de constituição de sujeitos e de subjetividades, para os diferentes regimes de verdade sobre o sujeito, para a dimensão política de constituição e reconhecimento de sujeitos e de suas zonas de exclusão, ou seja, os não sujeitos. 
Foucault (1995) e Butler (1997) argumentam que não há como pensar na construção de uma noção substantivista de sujeito, pois suas inscriçõos nas configurações hegemônicas são ambíguas, em constante construção e atravessadas por diversos fatores, de forma dinâmica, o que de certa forma, as experiências dos sujeitos da pesquisa deixaram transparecer. As experiências de Eva, Daniel, Nilza, Roger e de outros/as interlocutores/as demonstraram que a possibilidade de ocupar o lugar de sujeito aparece em determinados contextos, onde determinadas configurações são possíveis e desaparece em outros, onde o sujeito tido como "louco/a", e enunciado como tal, perde o lugar, a voz e a possibilidade de emergir.

Ainda que hegemonicamente compreendido, nas sociedades ocidentais contemporâneas como um ente individualizado, na concepção crítica das teorias sociais contemporâneas, o sujeito não é uma substância acabada, uma vez que, mesmo que sujeitado a, como proposto por Foucault (1995), tal sujeição se dá em relações complexas de poder. Para Foucault, são tais relações que permitem que se vislumbrem as estratégias de poder como um conjunto de meios operados para fazer funcionar ou manter um dispositivo de poder. Nessas relaçôes estão implicadas estratégias de luta e resistência.

Em certo sentido, Foucault (1995) sugere que para compreender as relações de poder talvez devêssemos analisar as formas de resistência destas/nestas relações, e assim parece necessário pensar nos sujeitos nos processos de desinstitucionalização psiquiátrica. Trata-se, então, de questionar como os diferentes saberes se inscrevem na vida das pessoas que, estando ou não em instituições asilares, se institucionalizam de outros modos, seja nas práticas de saúde, seja em suas experiências cotidianas e em tantos outros processos que dominam os modos de subjetivar na contemporaneidade.

Os grandes dispositivos de assujeitamento no interior dos quais o sujeito irá constituir-se, tal como o hospital psiquiátrico, foram estudados por Foucault (1987), que se referindo às instituiçōes psiquiátricas diz que as mesmas, na passagem para a era moderna, deixam de ser um lugar de depósito, como o asilo da era clássica, para ser um lugar de constituição de verdades, de individualização e normalização dos comportamentos e de modos de subjetivação. Como que dando prosseguimento aos estudos de Foucault, Deleuze desenvolveu a ideia de que as 
sociedades disciplinares, após a crise das disciplinas no período pós-segunda guerra, seriam lentamente transformadas em sociedades de controle (DELEUZE, 1992).

Para Deleuze (1996), a sociedade disciplinar era monitorada por suas instituições de disciplina e vigilância, enquanto que a sociedade de controle funcionaria por intermédio de redes flexíveis, modulares, estendendo seus domínios de ação sobre a subjetividade. Uma das características do poder no contemporâneo é que ele é também molecular. Ele não se exerce apenas de fora, de cima, dos lados, mas de dentro. Quem já teve uma "crise" deve estar atento, vigilante, sob controle.

No contexto da reforma psiquiátrica brasileira, também é possível reconhecer esta molecularização do poder na transformação das práticas de saúde mental que, um pouco mais distantes do hospital psiquiátrico, se disseminam em práticas territoriais, psicossociais, de intervenção, mas também de controle e disciplina.

\section{Desinstitucionalização, micropolíticas e estratégias terapêuticas}

Como já apresentamos, nossos/as interlocutores/as eram pessoas que tinham em comum o fato de frequentarem ou já terem frequentado serviços de saúde mental, terem sido internadas em hospitais psiquiátricos bem como fazerem ou já terem feito uso de algum tipo de psicofármaco. De certa maneira, tais aspectos estão relacionados ao fato de as mesmas terem experimentado momentos definidos por elas como "de crise", ou seja, situações limites de sofrimento que as conduziram aos serviços de saúde mental. Contudo, dizer que as trajetórias e experiências dessas pessoas eram marcadas por algum tipo de "crise" não significa dizer que elas necessariamente eram centrais ou definidoras em suas vidas, mas sim que desencadearam acontecimentos relacionados ao campo da saúde mental como, por exemplo, a procura por algum tipo de resolução das mesmas.

Tal como percebemos, o surto ou a crise seriam momentos privilegiados em que a loucura apareceria numa espécie de desvario, como a impossibilidade de manter a coesão necessária dos códigos compartilhados socialmente, marcando a trajetória e as experiências do sujeito. A partir desse momento, o sujeito acometido pela crise ou surto passa a "ser" louco, "ter" um diagnóstico e "estar" na iminência de novos surtos. 
A vulnerabilidade que esta condição impõe coloca o sujeito numa condição de precariedade extrema, onde aquilo que ele fala, pensa ou sente está sendo sempre submetido ao juízo alheio. Durante uma conversa que tivemos com Augusto e Bruno, dois interlocutores, esta condição ficou muito evidente. Durante a conversa, Bruno começou a contar sobre o desentendimento que havia tido com um de seus vizinhos em função de seu animal de estimação. O desentendimento não causou surpresa, já que parecia bastante comum no cotidiano das cidades. No entanto Augusto, que tinha escutado e questionado Bruno sobre o fato, em determinado momento da conversa perguntou: "tá, mas ele [o vizinho] fez isso mesmo, ou isso é coisa da tua cabeça?” Bruno olhou para ele e, pensativo, disse não saber.

Bruno, que até então parecia confiante de sua posição no episódio que tinha experimentado com seu vizinho, foi colocado à prova, não por ter ou não legitimidade no mesmo, mas pela possibilidade de estar destituído da sua razão.

Vale dizer que Bruno e Augusto, apesar de serem de geraçōes diferentes, tinham tido experiências parecidas. Ambos haviam sido internados em hospitais psiquiátricos, feito tratamento nos serviços substitutivos ou em consultórios médicos privados e usavam o mesmo tipo de medicação. Bruno havia interrompido seus estudos em função de seus problemas e desde então estudava em casa livros que escolhia conforme sua vontade. Morava com os pais, de quem em geral estava acompanhado. Já Augusto teve que sair do trabalho e vivia, naquele momento, da sua aposentadoria. Participava ativamente de cursos, grupos e outras atividades que o mantinham "ativo", à diferença de Bruno, e isso era um dos requisitos que também o autorizava a comentários deste tipo.

O "surto" / a "crise", nesse contexto, parece ser caracterizada como um momento radical em que o sujeito desaparece junto com o suposto desaparecimento de sua razão. Ainda que o sujeito saia da crise, do seu surto, ele parece estar sempre sob o risco de ter outros e é nessas condiçóes que passa a se experimentar no mundo.

Tais situações remetem aos argumentos de Pelbart (2009), de que o louco é concebido como sendo aquele que não sabe, não pode e não é sujeito. $\mathrm{O}$ autor chama atenção para o caráter violento presente nestas três instâncias (saber, poder e subjetividade) e a necessidade de se pensar outras possibilidades para a loucura. Nesse sentido, são sujeitos que estão atravessados não apenas por suas experiências singulares com a loucura, mas por relações complexas de poder e resistência. ${ }^{5}$

Seria necessário, em primeiro lugar, colocar tais sujeitos no centro dos processos de desinstitucionalização e ouvi-los de diferentes maneiras. Como sugeriu Pelbart 
(1993, p. 12), seria preciso deixar-se atravessar pela loucura, menos como sintoma e

mais como possibilidade, considerando o que ela "dispara e conturba em nós". Assim, mesmo aquela fala e/ou comportamento que possa nos parecer completamente destituídos de sentido, quando escutados deixam ver alguns pontos que, colocados em relação, ganham sentido. Trata-se, de certa forma, de buscar "escutar" quem está "invisível”, as "vozes" e, assim, entender quais os caminhos que poderiam constituir novamente uma possibilidade subjetiva minimamente habitável.

Uma referência da reforma psiquiátrica brasileira e que contribui para esta discussão é a chamada "clínica ampliada", apresentada também como a "clínica do sujeito" por ter nesse sua centralidade. Tal sujeito, nesta clínica, é sempre histórico, social, biológico e subjetivo, e vai além de sua condição de "doente". Esta clínica está baseada numa visão que relativiza o olhar eminentemente técnico ou clínico e onde a ênfase é colocada na invenção de modos de construir saúde, através de diferentes "tecnologias", como sugere Campos (2001).

No contexto da reforma psiquiátrica brasileira, é possível perceber uma heterogeneidade de práticas que se vinculam a abordagens teóricas diversas. Ao contrário do que ocorreu na realidade italiana, em que ainda hoje não se fala de uma "clínica" desenvolvida nos serviços, no Brasil, tal "clínica" foi se constituindo conforme a formação dos profissionais que atuavam nos serviços de saúde mental, o que se mantém até os dias de hoje. Com relação aos ditos psicóticos, uma série de questôes se impõe, especialmente, sobre as práticas de atenção psicossocial e a chamada clínica do sujeito e a clínica da psicose.

Desde o início do processo da reforma psiquiátrica brasileira, algumas propostas sobre tal "clínica" vêm ganhando espaço. No livro intitulado Clínica da Psicose: um projeto na rede pública, Goldberg (1996, p. 21) discutiu o projeto de transformação da assistência psiquiátrica na cidade de São Paulo e sugeriu que a "clínica da psicose" recusaria "o modelo sintomatológico em benefício da criação de uma clínica psiquiátrica renovada, deslocando o processo de tratamento da figura da doença para a pessoa doente”.

Para Costa (1996, p. 14), que fez a apresentação do livro de Goldberg (1996), "a chamada "clínica das psicoses" se resumiria a acompanhar, passo a passo, a trajetória de vida das pessoas na instituição". Para o autor

Acompanhar o percurso de vida das pessoas, como propõe o CAPS significa perguntar, a cada etapa da assistência, o que representa para o sujeito moral ser definido a partir de tal ou qual enquadre teórico. Significa perguntar o que ele ganha ou perde 
em autonomia, respeito por si próprio e pelo outro, quando exposto a certos procedimentos terapêuticos. (COSTA, 1996, p. 16).

Trata-se, desta forma, de compreender como as diferentes abordagens teóricas presentes na reforma psiquiátrica se aproximam, mais ou menos, dessa clínica ampliada e se conseguem manter ativos seus objetivos. Tal clínica significaria, nos termos dos autores, colocar o sujeito no centro das práticas, tarefa tão complexa quanto à de abrir portas. Como sugeriu Muñoz (2009, p. 7):

[...] é a clínica da psicose que ensina sobre a clínica em geral. E ela ensina justamente que pode haver uma variedade de soluções, de arranjos, de possibilidades para além daquilo que os tratamentos standard preconizam. É preciso então aplicar a psicose aos diversos saberes vigentes e não o contrário, ou seja, é preciso que estejamos dispostos a aplicar giros conceituais em nossos saberes prévios, operando modificações teóricas e recolhendo consequências clínicas.

Aplicar giros conceituais implicaria, nesse sentido, em perceber que as experiências dos sujeitos estão marcadas pelas características e circunstâncias dos contextos dos quais são parte; pela maior ou menor possibilidade de constituição de estratégias micropolíticas por parte dos sujeitos bem como pela adesão ou subversão ao regime psiquiatrizante ainda hegemônico na contemporaneidade. Como vimos, tal regime, alicerçado no pressuposto do sujeito da razão, faz desaparecer qualquer possibilidade de constituição dos mesmos nos momentos de "crise".

Nosso objetivo neste artigo não foi o de propor um caminho clínico ou terapêutico para os dilemas da reforma psiquiátrica, mas discutir as estratégias micropolíticas dos sujeitos da reforma psiquiátrica, com ênfase nas estratégias dos/as "usuários/as" ao lidar com a lógica e a linguagem biomédica. Por fim, entendemos que a contribuição da pesquisa etnográfica nesse campo é de, levando a sério o ponto de vista dos sujeitos, proporcionar elementos para a construção de outras maneiras de operar com esses sujeitos ("usuários" dos serviços de saúde mental) e suas experiências com a loucura, de relativizar de forma insistente as mesmas e de lidar de forma criativa com o que eles produzem. Conseguir escutar e operar com tais modalidades talvez seja um dos desafios para os processos de desinstitucionalização desencadeados pela reforma psiquiátrica brasileira. ${ }^{7}$ 


\section{Referências}

AMARANTE, P. O homem e a serpente: outras histórias para a loucura e a psiquiatria. Rio de Janeiro: Fiocruz, 1996. 141p.

ALVES, F. Racionalidades leigas sobre saúde e doença mental: um estudo no norte de Portugal. In: FONTES, B. A.S.M.; FONTE, E. M.M. da. Desinstitucionalização, redes sociais e saúde mental: análise de experiências da reforma psiquiátrica em Angola, Brasil e Portugal. Recife: Ed. Universitária da UFPE, 2010. p.25-70.

BASAGLIA, F. O. Manicomio Perchè? Roma: Editora Centro Franco Basaglia, 2001. 83p.

BOTT, E. Família e rede social. Rio de Janeiro: Francisco Alves, 1976. 319p.

BRASIL. Política Nacional de Saúde Mental. Brasília: Ministério da Saúde, 2001.

BUTLER, J. The psychic life of power: theories in subjection. Standford: Standford Univ. Press, 1997. 228p.

CAMPOS, R. O. Clínica: a palavra negada: sobre as práticas clínicas nos serviços substitutivos de Saúde Mental. Revista Saúde em Debate, v. 5, n. 58, p. 98-111, 2001.

CARDOSO, M. Psiquiatria e Antropologia: notas sobre um debate inconcluso. Revista Ilha, Florianópolis, v. 4, n. 1, p. 85-113, 2002.

COLEMAN, R. Lavorare per guarire. Carcare: Magema \& Cooperativa sociale "Il Casello", 2004. 100p.

COOPER, D. Psiquiatria e antipsiquiatria. 2ed. São Paulo: Perspectiva, 1989. 146p.

DELEUZE, G. Conversaçôes: 1972-1990. Rio de Janeiro: Ed. 34, 1992. 226p.

. Foucault. São Paulo: Brasiliense, 2005. 143p.

. O mistério de Ariana. Lisboa: Vega, 1996. 104p.

DELEUZE, G.; GUATTARI, F. Mil platôs: capitalismo e esquizofrenia. Volume IV. São Paulo: Ed. 34, 2007. 170p.

FIGUEIRA, S. Psicanalistas e pacientes na cultura psicanalítica. In: FIGUEIRA, S. et al. Efeito Psi: a influência da psicanálise. Rio de Janeiro: Campus, 1988. p.131-149.

FOUCAULT, M. História da loucura na idade clássica. 5ªed. São Paulo: Editora Perspectiva, 1997. 560p.

Microfísica do poder. Rio de Janeiro: Graal, 2009 [1979]. 295p.

. O sujeito e o poder. In: DREYFUS, H.; RABINOW, P. Michel Foucault, uma trajetória filosófica: para além do estruturalismo e da hermenêutica. Rio de janeiro: Forense Universitária, 1995. p.231-249.

. Vigiar e Punir: nascimento da prisão. $8^{\mathrm{a}}$ ed. Petrópolis: Vozes, 1987. 288p. 
GOFFMAN, E. Manicômios, prisóes e conventos. $7^{\text {a }}$ Ed. São Paulo: Perspectiva, 2001. 315p. GOLDBERG, J. Clínica da psicose: um projeto na rede pública. 2aed. Rio de Janeiro: Te Corá / Instituto Franco Basaglia, 1996. 168p.

GUATTARI, F.; ROLNIK, S. Micropolítica: cartografias do desejo. 9a ed. Petrópolis: Vozes, 2008. 330p.

MALUF, S. W. Antropologia do sujeito e políticas da vida: uma reflexão sobre biopolítica, experiências sociais e modos de subjetivação no contexto das políticas de saúde mental no Brasil. Florianópolis, 2011 (mimeo).

Gênero, saúde e aflição: políticas públicas, ativismo e experiências sociais. In: MALUF, S. W.; TORNQUIST, C. S. (Org.). Gênero, saúde e aflição: abordagens antropológicas. Florianópolis: Letras Contemporâneas, 2010. p. 21-68.

MUÑOZ, N. M. Na polifonia de uma orquestra: uma pesquisa clínica com grupos sobre a experiência alucinatória. 2009. Disponível em: <http://www.fundamentalpsychopathology. org/material/coloquio_metodo_clinico/MR/MR01.2.pdf> Acesso em: 25 jun.2013

PELBART, P. P. A nau do tempo-rei: sete ensaios sobre o tempo da loucura. Rio de Janeiro: Imago, 1993. 132p.

Da clausura do fora ao fora da clausura: loucura e desrazão. 2 ed. São Paulo: Iluminuras, 2009. 240p.

. Vida Capital: ensaios de biopolítica. São Paulo: Iluminuras, 2003. 252p.

PORTER, R. "Expressando sua enfermidade": a linguagem da doença na Inglaterra Georgiana. In: BURKE, P.; PORTER, R. Linguagem, individuo e sociedade: história social da linguagem. São Paulo: Unesp, 1994. p. 365-394.

ROTELli, F.; LEONARDIS, O.; MAURI, D. Desinstitucionalização. São Paulo: Hucitec, 2001. 112p.

SCOTT, J. Experiência. In: SILVA, A.; LAGO, M. C. de S.; RAMOS, T. R.O. Falas de gênero: teorias, análises, leituras. Florianópolis: Mulheres, 1999. p. 21-55.

\section{Notas}

${ }^{1}$ A pesquisa subsidiou uma tese de doutorado, financiada pela CAPES/CNPq e pelo Instituto Brasil Plural (INCT/CNPq) e aprovada no Comitê de Ética da Universidade Federal de Santa Catarina, conforme Parecer 355/06.

${ }^{2}$ Todos os nomes são fictícios.

${ }^{3}$ A expressão "usuários/as" foi substituída durante o processo de pesquisa pela expressão "experientes". Tal substituição levou em conta os argumentos de Maluf (2010) e Coleman (2004), no entendimento de que as experiências destes sujeitos são muito importantes e o fato de que eles fazem muito mais do que "usar" os serviços. Como tal discussão não foi contemplada aqui, utilizamos a expressão usuários/as entre aspas para relativizar a mesma. 
${ }^{4}$ Sobre a circulação das linguagens biopsicomédicas, ver Porter (1994) e Figueira (1988).

${ }^{5} \mathrm{Na}$ construção de seu argumento em relação às potências da loucura, Pelbart dialoga com as discussôes de Foucault e de Deleuze sobre os campos de força que atuam no sentido da constituição da subjetividade. A noção de Fora é uma das figuras centrais dessa discussão, ao mesmo tempo zona da loucura para onde escapa a impossibilidade de subjetivação e zona de turbulência e resistência. (DELEUZE, 2005).

${ }^{6}$ Como "clínica", estamos nos referindo aqui "às práticas não somente médicas, mas de todas as profissões que lidam no dia-a-dia com diagnóstico, tratamento, reabilitação e prevenção secundária”, como sugeriu Campos (2001).

${ }^{7}$ A. P. M. de Andrade participou da concepção e redação do artigo. S. W. Maluf participou da concepção e redação do artigo, e realizou a revisão crítica do texto. 
Subjects and (in) experience: micropolitical strategies in the context of the psychiatric reform in Brazil

This article discusses the institutionalization of processes triggered by the Brazilian psychiatric reform and the micro-political strategies related to these processes. The data supporting our discussions come from an ethnographic research conducted in the years 2010 and 2011, in the Brazilian cities of Joinville, Santa Catarina state, and Barbacena, Minas Gerais state, as well as in Turin, Trieste and Gorizia, in Italy, aiming to develop a critical analysis of the Brazilian psychiatric reform from the perspective of the so-called users of mental health services. The issues discussed here show how the experiences of the subjects in these services are marked by the definition of relational and hierarchical places, and also by complex processes of subjectivation, in which micro strategies of subjection and resistance engender. Their experiences and ways of acting in the deinstitutionalization process point to the need for construction of different ways to work with the concepts related to the subjects.

> Key words: psychiatric reform; deinstitutionalization; modes of subjectivation; experience; micropolitics. 